\title{
Mental health of UK military personnel while on deployment in Iraq
}

Kathleen Mulligan, Norman Jones, Charlotte Woodhead, Mark Davies, Simon Wessely and Neil Greenberg

\section{Background}

Most research on the mental health of UK armed forces personnel has been conducted either before or after deployment; there is scant evidence concerning personnel while they are on deployment.

\section{Aims}

To assess the mental health of UK armed forces personnel deployed in Iraq and identify gaps in the provision of support on operations.

\section{Method}

Personnel completed a questionnaire about their deployment experiences and health status. Primary outcomes were psychological distress (General Health Questionnaire-12, GHQ-12), symptoms of post-traumatic stress disorder (PTSD) and self-rating of overall health.

\section{Results}

Of 611 participants, $20.5 \%$ scored above the cut-off on the GHQ-12 and 3.4\% scored as having probable PTSD. Higher risk of psychological distress was associated with younger age, female gender, weaker unit cohesion, poorer perceived leadership and non-receipt of a pre-deployment stress brief. Perceived threat to life, poorer perceived leadership and non-receipt of a stress brief were risk factors for symptoms of PTSD. Better self-rated overall health was associated with being a commissioned officer, stronger unit cohesion and having taken a period of rest and recuperation. Personnel who reported sick for any reason during deployment were more likely to report psychological symptoms. Around $11 \%$ reported currently being interested in receiving help for a psychological problem.

\section{Conclusions}

In an established operational theatre the prevalence of common psychopathology was similar to rates found in nondeployed military samples. However, there remains scope for further improving in-theatre support mechanisms, raising awareness of the link between reporting sick and mental health and ensuring implementation of current policy to deliver pre-deployment stress briefs.

\section{Declaration of interest}

N.G. and M.D. are full-time active service members of the armed forces. N.J. is a full-time reserve member of the Defence Medical Services. S.W. is an honorary civilian consultant advisor in psychiatry to the British army (unpaid). K.M. and C.W. are employed by the Academic Centre for Defence Mental Health, which receives funding from the UK Ministry of Defence.
Much is already known about the mental health of UK armed forces personnel. ${ }^{1-5}$ However, most research to date has examined the psychological well-being of military personnel either before or after deployment relying on retrospective accounts to examine the impact of deployment experiences; there is currently scant evidence concerning the psychological health status of personnel while they are deployed on operations. It is known that relatively small numbers access field mental health teams (the unit by which formal mental health is delivered on operations) ${ }^{6,7}$ but these figures are unlikely to be a true reflection of the prevalence of mental health problems since there is a considerable body of evidence that suggests that significant numbers of personnel who might benefit from mental healthcare or support do not access services because of stigma. ${ }^{8-10}$

Since 2003, the US military have been conducting annual surveys of the psychological health of personnel while on deployment to Iraq and, to a lesser extent, Afghanistan. ${ }^{11}$ Their findings have helped to inform policy and practice changes. For example, they have decreased their standard tour length from 15 to 12 months and increased the numbers of deployed mental health providers to bolster the support options available to deployed personnel. This paper reports the findings of the first systematic survey of UK armed forces personnel while on deployment, which was conducted to evaluate their mental health status and factors that may affect their psychological health, as well as to identify any obvious gaps in the provision of support on operations.

\section{Method}

The study was conducted in Iraq in January and February 2009 during Operation TELIC 13 (the deployment period between December 2008 and June 2009). Operation TELIC is the codename for UK military operations in Iraq since 2003. Participants were eligible for the study if they were members of any of the three UK armed forces (Royal Navy, army and Royal Air Force), and were deployed in Iraq during the study datacollection period. The target sample size was 600 personnel, representing approximately $15 \%$ of the deployed force; half based within the main base in Basra (known as the Contingency Operating Base) and half outside. True random sampling was not possible because of the need to ensure an adequate coverage of personnel from very small operating bases, and operational reasons (this was a theatre of war); special forces personnel were not included in the sample. Instead, after discussion with the medical and personnel staff officers based in the UK operational headquarters, purposive sampling was conducted to ensure an adequate spread of personnel and locations. Information on the service and rank profile of the deployed force was obtained from the divisional personnel report, allowing examination of the representativeness of the study sample.

Data were collected using a self-report questionnaire. The Operational Mental Health Needs Evaluation (OMHNE) survey team, which included two military personnel, travelled to eight 


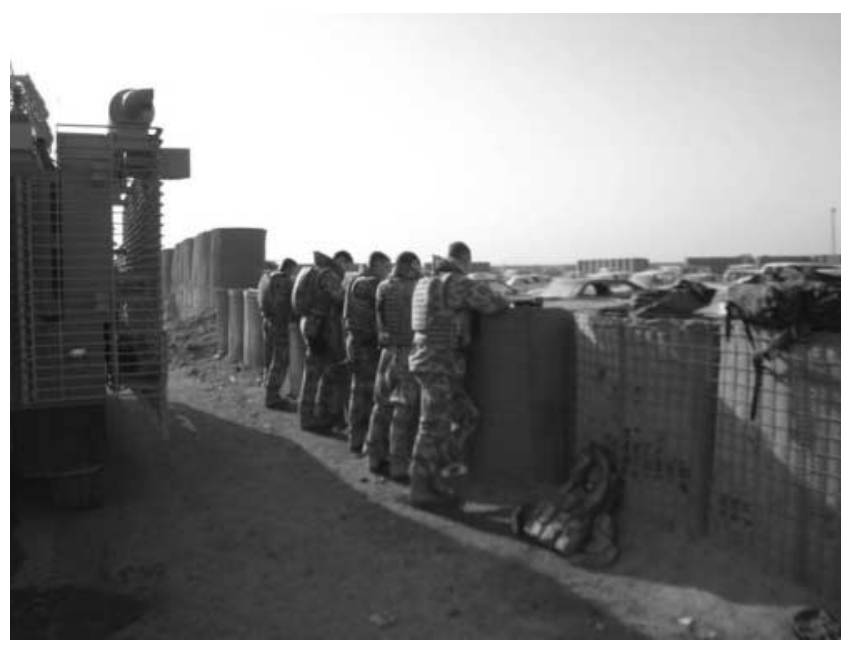

Fig. 1 Completing the Operational Mental Health Needs Evaluation questionnaire.

locations to distribute and collect questionnaires (Fig. 1). The locations included not just the main base in Basra, but also Baghdad, locations in Basra City and other units deployed across Southern Iraq. All the main UK bases were visited, excluding some remote locations. Location commanders were asked to assemble all available personnel so that the survey team could provide information about the study and distribute questionnaires. The survey team were explicit in briefing the potential respondents that, unlike other deployment activities, completion of the questionnaires was voluntary. Personnel were also assured that all information was confidential, that their individual responses would not be reported to commanders and that no individual would be named in any report about the study. Respondents were informed that personal identification information would be separated from the questionnaire by the study team and stored separately. The questionnaire took approximately $25 \mathrm{~min}$ to complete. Participants were not given any payment or any other inducement for taking part in the study. Once completed, participants placed their questionnaire in an envelope and sealed it before giving it to a member of the study team.

The survey tool included questions about sociodemographic and military characteristics, deployment experiences, unit factors such as cohesion and leadership, and force health protection factors such as receipt of a stress brief and taking a period of rest and recuperation (R\&R) in a location outside the operational theatre. The primary outcome measures assessed were: psychological distress, symptoms of post-traumatic stress disorder (PTSD), and self-rated health. Psychological distress was assessed with the 12-item General Health Questionnaire (GHQ-12), ${ }^{12}$ with those scoring four or more classified as 'cases'. Symptoms of PTSD were measured with the 17-item National Center for PTSD Checklist (PCL-C), ${ }^{13}$ with cases defined as those scoring 50 or more. The GHQ-12 and PCL-C have been routinely used in a variety of studies conducted into the health of UK armed forces personnel in non-deployed settings. Self-reported health status was assessed with a single item that asked respondents to rate their health from poor to excellent on a five-point Likert scale. Participants were also asked about reported sickness and helpseeking during the deployment. Combat exposure was assessed with a 17-item measure that asked about the frequency of exposure to potentially traumatic combat events. Unit cohesion and leadership were each assessed with four-item measures that have been used in other studies of health in the UK armed forces. ${ }^{5}$ A number of other issues were also assessed in the questionnaire; however, this paper concentrates on deployment-related factors and their possible impact on health.

Approval to conduct the study was granted by the Ministry of Defence Research Ethics Committee (MODREC) (Protocol No. 839/194). All participants gave written informed consent.

\section{Analysis}

Analyses were carried out in STATA 10.1 for Windows. Statistical significance was defined at the level of $P<0.05$. The association between independent variables (demographic and military characteristics, deployment experiences, unit cohesion, leadership and health protection factors) and health outcomes was examined using regression analyses. Psychological distress (caseness as assessed by the GHQ-12) was examined using binary logistic regression analyses to generate odds ratios (ORs). Because of the small number of PTSD cases, the study did not have sufficient power to treat this as a dichotomous variable in multivariate analyses. Instead, the measure was used as a continuous scale. As the data were highly skewed, negative-binomial regression analysis was conducted, using the PCL-C score as a count variable. The PCL-C total score was recoded from 17 to 85 to range from 0 to 68 for the purpose of the regression analysis. Self-rated health was assessed on an ordinal scale, therefore ordinal regression analysis was used to examine the association between independent variables and self-rated overall health. As very few respondents rated their health as 'poor', the responses 'poor' and 'fair' were combined, producing a four-point scale: excellent, very good, good and fair/poor.

The relationship between reporting sick during deployment and the self-report mental health outcomes were analysed using $\chi^{2}$-tests for GHQ-12 and Mann-Whitney $U$-tests for PCL-C.

\section{Results}

Of 612 personnel approached to take part, 611 (99.8\%) completed the survey. This represented approximately $15 \%$ of the UK armed forces personnel deployed in Iraq on Operation TELIC 13. Sample characteristics are described in Table 1, which indicates that, in terms of service and rank, the sample is broadly representative of the deployed population.

\section{Health outcomes}

Health outcomes are shown in Table 2. In total, 125 of the 602 respondents who completed the GHQ-12 (20.8\%) were classified as cases. Of the 588 respondents who completed the PCL-C (3.4\%), 20 were classified as PTSD cases. Most respondents $(n=564 / 609,92.6 \%)$ reported their overall health to be good, very good or excellent.

\section{Risk factors and self-reported health status}

Those who scored above the cut-off on the GHQ-12 were more likely to be younger, female, in the army and of junior rather than of senior or officer rank (online Table DS1). Stronger unit cohesion, better perceived leadership and receipt of a predeployment stress brief were associated with a lower likelihood of scoring above the GHQ-12 cut-off. There was no relationship between GHQ-12 outcome and reservist status or deployment factors such as location in theatre or combat exposure. In multivariate analysis, the variables that remained statistically 
Table 1 Demographic characteristics of the Operational Mental Health Needs Evaluation (OMHNE) sample studied in relation to the total Operation TELIC 13 population

\begin{tabular}{|lcc|}
\hline & $\begin{array}{c}\text { OMHNE sample } \\
(n=611)^{\mathrm{a}}\end{array}$ & $\begin{array}{c}\text { Operation TELIC 13 } \\
\text { population }\end{array}$ \\
\hline $\begin{array}{l}\text { Service, } n \text { (\%) } \\
\text { Naval service }\end{array}$ & $39(6)$ & $164(4)$ \\
Army & $497(82)$ & $3200(81)$ \\
Royal Air Force & $75(12)$ & $591(15)$ \\
\hline $\begin{array}{l}\text { Rank, } n \text { (\%) } \\
\text { Officer } \\
\text { Senior non-commissioned officer } \\
\text { Junior rank }\end{array}$ & $76(12)$ & $573(14)$ \\
\hline Gender, $n$ (\%) & $102(17)$ & $700(18)$ \\
Male & $431(71)$ & $2682(68)$ \\
\hline Female & $542(89)$ & 13.3 \\
\hline Age, years: median (interquartile range) & $69(11)$ & 14.6 \\
\hline a. Numbers may not add up to 611 because of missing data. Percentages may not add up to 100 because of rounding.
\end{tabular}

\section{Table 2 Health outcomes in Operational Mental Health Needs Evaluation (OMHNE) sample $(n=611)^{\text {a }}$ during the current deployment}

\begin{tabular}{|c|c|}
\hline & $n(\%)$ \\
\hline \multicolumn{2}{|l|}{ Overall health rating } \\
\hline Excellent & $150(24.6)$ \\
\hline Very good & $237(38.9)$ \\
\hline Good & $177(29.1)$ \\
\hline Fair & $41(6.7)$ \\
\hline Poor & $4(0.7)$ \\
\hline \multicolumn{2}{|l|}{ Psychological health } \\
\hline Psychological distress: General Health & \\
\hline Questionnaire-12 case & $125(20.8$ \\
\hline Probable post-traumatic stress disorder: & \\
\hline PTSD Checklist case & $20(3.4)$ \\
\hline \multicolumn{2}{|l|}{ Number of times reported sick during deployment } \\
\hline 0 & $469(77.1)$ \\
\hline $1-2$ & $129(21.2$ \\
\hline $3+$ & $10(1.6)$ \\
\hline Seen at field hospital & $34(5.6)$ \\
\hline $\begin{array}{l}\text { Experienced a significant stressful, emotional or family } \\
\text { problem }\end{array}$ & $151(25.5$ \\
\hline $\begin{array}{l}\text { Interested in receiving help for a significant stressful, } \\
\text { emotional or family problem }\end{array}$ & $58(10.6)$ \\
\hline
\end{tabular}

significant independent risk factors were: younger age, female gender, weaker unit cohesion, poorer perceived leadership and non-receipt of a stress brief.

An increased risk of reporting PTSD symptoms was associated with junior rank, having felt in danger of being killed and higher combat exposure (online Table DS2). Better perceived leadership and receipt of a stress brief were associated with a lower risk of reporting PTSD symptoms. In multivariate analysis, the variables that remained statistically significant independent risk factors for reporting symptoms of PTSD were having felt in danger of being killed, poorer perceived leadership and non-receipt of a stress brief.

Poorer overall self-rated general health was associated with non-officer rank, reservist status, poorer unit cohesion, poorer perceived leadership, non-receipt of a stress brief and not having taken a period of $\mathrm{R} \& \mathrm{R}$ (online Table DS3). In multivariate analysis, the variables that remained statistically significant independent risk factors for poorer self-rated health were non-officer rank, poorer unit cohesion and not having taken a period of $R \& R$.

\section{Relationship between help-seeking during deployment and mental health}

Personnel who reported sick on at least one occasion for any reason were significantly more likely than those who had not reported sick to score above the cut-off on the GHQ-12. They also reported significantly more symptoms of PTSD (Table 3). Admission to the field hospital did not significantly affect the likelihood of scoring above the cut-off on the GHQ-12 or reporting symptoms of PTSD.

Those who reported having experienced a significant stressful, emotional or family problem were significantly more likely to score above the cut-off on the GHQ-12 and to report more symptoms of PTSD (Table 3 ). Of those who reported having experienced a problem during the deployment $(n=151,26 \%)$, less than $40 \%(n=56)$ reported having received help. Where help was received, it was most commonly from a friend $(n=38,68 \%$ of those who had experienced a problem and received help) or the chain of command $(n=24,43 \%)$. Help from a chaplain or medical professional was less common, being received by 10 $(18 \%)$ and $7(13 \%)$ respectively.

Those who were currently interested in receiving help for a significant stressful, emotional or family problem were significantly more likely to score above the cut-off on the GHQ-12 and to report more symptoms of PTSD (Table 3). Respondents who reported being currently interested in receiving help $(n=58)$ were more likely to be younger (mean age $25.3 v$. 27.9 years, $t=-2.5, P=0.01)$ and of junior $\operatorname{rank}\left(\chi^{2}=13.1\right.$, $P=0.001)$, however there was no association with service $\left(\chi^{2}=0.23, P=0.89\right)$ or gender $\left(\chi^{2}=0.003, P=0.96\right)$.

\section{Discussion}

\section{Main findings}

The OMHNE survey aimed to provide information about the health of deployed UK service personnel. Although the OMHNE was a novel process for the British armed forces, over 600 responses were successfully collected (with a $99.8 \%$ response rate), entered into a statistical database, analysed and briefed back to senior commanders within a 6-week period. This confirms that the OMHNE is a viable approach to obtaining real-time health online Table DS3 and personnel data on operations.

The OMHNE produced a number of key findings. First, the prevalence rates of psychological distress and PTSD found within this study are in keeping with those reported in other recent 


\begin{tabular}{|c|c|c|c|c|c|c|c|c|}
\hline & \multicolumn{4}{|c|}{ Psychological distress: GHQ-12 caseness } & \multicolumn{4}{|c|}{ Symptoms of PTSD: PCL-C continuous score } \\
\hline & $n$ in analysis ${ }^{b}$ & Cases, $n(\%)$ & $\chi^{2}($ d.f. $=1)$ & $P$ & $n$ in analysis ${ }^{b}$ & Median (IQR) & $Z^{c}$ & $P$ \\
\hline Reported sick at least once & & & 5.08 & 0.024 & & & -2.740 & 0.006 \\
\hline Yes & 137 & $38(27.7)$ & & & 135 & $21.0(18.0-28.0)$ & & \\
\hline No & 462 & $87(18.8)$ & & & 467 & $20.0(17.0-25.0)$ & & \\
\hline Admitted to field hospital & & & 2.88 & 0.090 & & & -0.920 & 0.358 \\
\hline Yes & 34 & $11(32.4)$ & & & 34 & $20.5(18.0-25.0)$ & & \\
\hline No & 565 & $114(20.2)$ & & & 568 & $20.0(17.0-25.0)$ & & \\
\hline $\begin{array}{l}\text { Experienced a significant stress, } \\
\text { emotional or family problem }\end{array}$ & & & 53.59 & $<0.0001$ & & & -7.670 & $<0.0001$ \\
\hline Yes & 151 & $63(41.7)$ & & & 151 & $23.0(20.0-33.0)$ & & \\
\hline No & 439 & $60(13.7)$ & & & 440 & $19.0(17.0-23.0)$ & & \\
\hline $\begin{array}{l}\text { Currently interested in receiving help for } \\
\text { a stress, emotional or family problem }\end{array}$ & & & 7.00 & 0.008 & & & -4.780 & $<0.0001$ \\
\hline Yes & 57 & $20(35.1)$ & & & 58 & $26.0(20.0-35.5)$ & & \\
\hline No & 483 & $96(19.9)$ & & & 485 & $20.0(17.0-25.0)$ & & \\
\hline $\begin{array}{l}\text { GHQ-12, General Health Questionnaire-12; PTSD } \\
\text { a. Statistically significant results }(P<0.05) \text { are hig } \\
\text { b. Numbers differ between GHQ-12 and PCL-C } \\
\text { c. Mann-Whitney U-test. }\end{array}$ & $\begin{array}{l}\text { post-traumatic str } \\
\text { lighted in bold. } \\
\text { nalyses because of }\end{array}$ & $\begin{array}{l}\text { s disorder; PCL-C } \\
\text { nissing data. }\end{array}$ & PTSD checklist & $\therefore$ IQR, interq & tile range. & & & \\
\hline
\end{tabular}

studies that surveyed UK armed forces personnel when they were not on deployment. ${ }^{1,5}$ So too are the reported ratings of overall health. ${ }^{14}$ These prevalence rates are lower than in other high-stress occupational groups such as police officers, doctors in emergency departments and disaster workers. ${ }^{15-17}$ Second, the data showed that the main risk factors for psychological distress (as measured by GHQ-12) were: female gender, weaker unit cohesion, poorer perceived leadership and non-receipt of a stress brief. The main risk factors for reporting symptoms of PTSD were: perceived threat to life, poorer perceived leadership and non-receipt of a stress brief. Third, better self-rated health was associated with officer rank, stronger unit cohesion and having taken a period of R\&R. Finally, we found that more than $10 \%$ of personnel were currently interested in receiving help for a stress, emotional or family problem; these were more likely to be individuals in the junior ranks.

Although there are reasons for hypothesising that, on the one hand deployed service personnel might experience better mental health than those not deployed, for example due to the 'healthy worker effect, ${ }^{18}$ but on the other hand worse mental health due to increased exposure to stressors, this survey found that in practice, there seemed to be little overall effect of deployment on mental health. It may be that the positive and negative aspects of deployment are equally balanced. Another possible explanation is that Operation TELIC 13 was a low operational intensity environment, which is often characteristic of a military operation coming towards its end. This explanation is supported by the most recent annual US survey of personnel deployed to Iraq, the Mental Health Advisory Team (MHAT) VI, which has reported the lowest rate of psychological problems since 2004. ${ }^{19}$

The relationship between demographic factors and health outcomes in the OMHNE was mostly consistent with findings of earlier studies in the UK armed forces. Reporting of better overall health by officers has been found in an earlier study of UK armed forces personnel ${ }^{14}$ and is thought to reflect the general finding of better self-rated health among those of higher socioeconomic status. ${ }^{20}$ The absence of any gender difference in symptoms of PTSD or self-rated health has been previously reported by Rona et al. ${ }^{14,21}$ However, the relation between gender and psychological distress assessed with the GHQ is not consistent across studies. In common with the OHMNE, Hotopf et $a l^{22}$ found that female personnel who had been deployed in Bosnia were more likely to score above the cut-off on the GHQ; however, among Gulf War veterans, this was more common among male veterans. ${ }^{23}$ Although this appears to be an area worthy of further investigation, this finding may represent different pressures on female service members while deployed compared with the home environment.

Deployment-related factors such as time spent outside the base in a hostile area, were mostly not significant risk factors for health problems. This is in contrast to findings from a study of UK personnel serving on earlier, more intensive, Iraq deployments, in which time spent in a forward area was a significant risk factor for PTSD. ${ }^{24}$ However, in the current study, although being in a hostile area was not in itself a risk factor for poorer mental health, feeling in danger of being killed was a risk factor for symptoms of PTSD, consistent with other studies. ${ }^{24,25}$ This indicates that the perceived danger of deployment is most salient and is consistent with Ehlers \& Clark's ${ }^{26}$ cognitive model of PTSD, which proposes that the perceived level of threat is more important than its actual severity in the development of PTSD.

It is encouraging that several of the variables that were associated with health outcomes in the multivariate analyses are potentially modifiable, i.e. unit cohesion, leadership, receipt of a stress brief and provision of R\&R. There has been much written about the benefits, in terms of mental health, of working within units that enjoy good leadership and good cohesion between unit members, ${ }^{24,27,28}$ and the modern military do not need to be reminded of the importance of cohesion and leadership on morale, mental health and military effectiveness. Social support offered by a cohesive unit and supportive leadership may also protect against physical ill health by acting as a buffer against the potentially negative impact of stressful events. ${ }^{29}$ The results of this study are consistent with these findings.

This study found that, unlike previous UK research into pre-deployment briefings carried out during Operation TELIC $1,{ }^{30}$ those who reported remembering having had a pre-deployment brief reported significantly better mental health than those who did not. It is possible that those units that ensure their personnel receive a pre-deployment briefing may also ensure that the well-being of unit members is protected in other ways. However, this effect was not simply related to the quality of unit leadership since the finding remained significant after the quality of leadership was controlled for. A similar finding 
was demonstrated by the US Mental Health Advisory Team who also found that units who reported receiving standardised pre-deployment educational packages had better mental health than those who did not; again the effect remained after controlling for leadership. ${ }^{31}$ Previous UK military research has shown that only those briefings that personnel recall as having been useful are likely to be beneficial in terms of mental health. ${ }^{32}$ Thus, the OMHNE finding may be as a result of pre-deployment briefings having become more salient and focused since Operation TELIC 1, perhaps as a result of the considerable experience that the UK armed forces now have in preparing personnel for deployment.

Our findings suggest that those who reported sick on at least one occasion had poorer self-reported mental health. Although this could be representative of comorbid psychological ill health with physical illness, this is not supported by the finding of minimal effects on mental health associated with being admitted to the field hospital. Although the OMHNE did not attempt to explore the reasons why personnel may have reported sick, it is well-known that the dynamics of the clinician-patient consultation is often more complex than the simple request by an individual for advice or treatment. ${ }^{33}$ Increased attentiveness to possible signs of mental health problems among those who report sick could help to identify those in need of help.

One strength of this study is that it achieved a very high response rate. The lower response rate found in other studies (e.g. Fear et al $)^{1}$ may well occur because of difficulty in locating a highly mobile population outside of a deployed environment rather than because of reluctance to take part in research.

\section{Implications}

The OMHNE study has identified a number of important areas regarding the psychological well-being and mental health of UK military personnel while deployed. A small but not insignificant number of personnel reported being interested in receiving help at the time of survey completion. However, only a small percentage of those who seek support do so from formal available sources (medical centres, welfare agencies or the field mental health teams), suggesting that barriers exist, either cognitively or practically, which prevent some personnel from accessing this support. Forward provision of such support is likely to make access easier, reduce the likelihood that internal stigma will act as a barrier and is in keeping with the psychiatric doctrine of

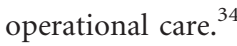

Most units have some in-house medical support, which can be delivered by medical assistants or combat medical technicians, who support the unit medical officer. Medical assistant/combat medical technicians training does not currently cover the nature of mental health disorders nor does it aim to prepare them to conduct a psychologically focused consultation. Raising awareness among medical assistant/combat medical technicians staff of the relationship between reporting sick and mental health, alongside further training in this area, may help to identify those in need of psychological help.

There is already joint policy that mandates that deploying personnel are provided with a pre-deployment brief. $^{35}$ The OMHNE data suggest that this policy needs to be more rigorously enforced while ensuring that the briefs are both suitable for the intended audience and of a good quality.

\section{Study limitations}

The small number of PTSD cases in this sample meant the study did not have sufficient power to examine risk factors for scoring above the threshold for having probable PTSD. However, our other larger studies have permitted such analysis, albeit not in an operational setting ${ }^{24}$ and comparisons with these findings have been discussed earlier. The small number of reservists in the study meant that we were unable to confirm or refute our previous work showing that reservists had significantly worse post-deployment mental health. ${ }^{3,5}$

The study used self-report measures and thus, in keeping with all such measures, it is not possible to diagnose mental ill health reliably; diagnosis requires a clinical interview (which was not done during OMHNE). Scoring over a specified level on the questionnaires increases the probability that an individual has a defined mental health disorder, but is not definitive. The questionnaires should therefore be considered more as screening than diagnostic instruments.

Since the OMHNE data were derived from a non-random sample of personnel, one might be cautious when generalising the findings to all personnel deployed to Operation TELIC 13 and to other operations. The sample was, however, selected only after discussion with in-theatre operational planners and all efforts were made by the OMHNE team to minimise selection bias by ensuring that everyone who was off-duty at a unit location completed a questionnaire. It may be, however, that those who did not want to complete questionnaires made themselves unavailable during visits by the research team. Conducting an epidemiological study in a war zone inevitably entails difficulties in accessing all eligible personnel. However, the OMHNE sample is similar in terms of rank and service to the Operation TELIC 13 population from which it is drawn (Table 1), which offers some reassurance that we did not have significant recruitment bias.

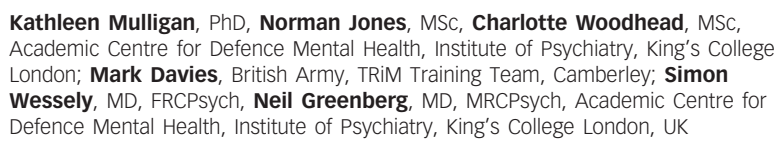

Kathleen Mulligan, PhD, Norman Jones, MSC, Charlotte Woodhead, MSC, Academic Centre for Defence Mental Health, Institute of Psychiatry, King's College London; Mark Davies, British Army, TRiM Training Team, Camberley; simon Wessely, MD, FRCPsych, Neil Greenberg, MD, MRCPsych, Academic Centre for Defence Mental Health, Institute of Psychiatry, King's College London, UK

Correspondence: Neil Greenberg, Academic Centre for Defence Mental Health, 3rd Floor, Weston Education Centre, Cutcombe Road, London SE5 9RJ, UK. Email: sososanta@aol.com

First received 4 Jan 2010, final revision 17 May 2010, accepted 22 Jul 2010

\section{References}

1 Fear NT, Jones M, Murphy D, Hull L, Iversen A, Coker B, et al. What are the consequences of deployment to Iraq and Afghanistan on the mental health of the UK armed forces? A cohort study. Lancet 2010; 375: 1783-97.

2 Tarn M, Greenberg N, Wessely S. Gulf War syndrome - has it gone away? Adv Psychiatr Treat 2008; 14: 414-22.

3 Iversen AC, van Staden L, Hacker Hughes J, Browne T, Hull L, Hall J, et al. The prevalence of common mental disorders and PTSD in the UK military: using data from a clinical interview-based study. BMC Psychiatry 2009; 9: 68.

4 Wessely S. Risk, psychiatry and the military. Br J Psychiatry 2005; 186 459-66.

5 Hotopf M, Hull L, Fear NT, Browne T, Horn O, Iversen A, et al. The health of UK military personnel who deployed to the 2003 Iraq war: a cohort study. Lancet 2006; 367: 1731-41.

6 Greenberg N, Browne T, Langston V, McAllister P. Operational mental health: a user's guide for medical staff. J R Nav Med Serv 2007; 93: 5-11.

7 Jones N, Greenberg N, Fear NT, Earnshaw M, McAllister P, Reid G, et al The operational mental health consequences of deployment to Iraq for UK Forces. J R Army Med Corps 2008; 154: 102-6.

8 Langston V, Gould M, Greenberg N. Culture: what is its effect on stress in the military? Mil Med 2007; 172: 931-5.

9 Hoge CW, Castro CA, Messer SC, McGurk D, Cotting DI, Koffman RL. Combat duty in Iraq and Afghanistan, mental health problems, and barriers to care. N Engl J Med 2004; 351: 13-22. 
10 Gould M, Adler A, Zamorski M, Castro C, Hanily N, Steele N, et al. Do stigma and other perceived barriers to mental health care differ across Armed Forces? J R Soc Med 2010; 103: 148-56.

11 Castro CA, McGurk D. The intensity of combat and behavioral health status. Traumatology 2007; 13: 6-23.

12 Goldberg D, Williams P. A User's Guide to the General Health Questionnaire. nferNelson, 1988.

13 Weathers F, Litz B, Herman D, Huska J, Keane T. The PTSD Checklist - Civilian Version $(P C L-C)$. National Center for PTSD, 1994.

14 Rona RJ, Hooper R, French $\mathrm{C}$, Jones $\mathrm{M}$, Wessely $\mathrm{S}$. The meaning of selfperception of health in the UK armed forces. Br J Health Psychol 2006; 11: 703-15.

15 Collins PA, Gibbs AC. Stress in police officers: a study of the origins, prevalence and severity of stress-related symptoms within a county police force. Occup Med (Lond) 2003; 53: 256-64.

16 Perrin MA, DiGrande L, Wheeler K, Thorpe L, Farfel M, Brackbill R. Differences in PTSD prevalence and associated risk factors among World Trade Center disaster rescue and recovery workers. Am J Psychiatry 2007; 164: 1385-94.

17 Burbeck R, Coomber S, Robinson SM, Todd C. Occupational stress in consultants in accident and emergency medicine: a national survey of levels of stress at work. Emerg Med J 2002; 19: 234-8

$18 \mathrm{Li} \mathrm{CY}$, sung FC. A review of the healthy worker effect in occupational epidemiology. Occup Med (Lond) 1999; 49: 225-9.

19 Office of the Surgeon Multi-National Corps-Iraq and Office of The Surgeon General United States Army Medical Command. Mental Health Advisory Team (MHAT) VI. Operation Iraqi Freedom 07-09. Office of the Surgeon MultiNational Corps-Iraq and Office of The Surgeon General United States Army Medical Command, 2009 (http://www.armymedicine.army.mil/reports/mhat/ mhat_vi/MHAT_VI-OIF_Redacted.pdf).

20 Marmot MG, Smith GD, Stansfeld S, Patel C, North F, Head J, et al. Health inequalities among British civil servants: the Whitehall II study. Lancet 1991; 337: 1387-93.

21 Rona RJ, Fear NT, Hull L, Wessely S. Women in novel occupational roles: mental health trends in the UK Armed Forces. Int J Epidemiol 2007; 36: 319-26.

22 Hotopf M, David AS, Hull L, Ismail K, Palmer I, Unwin C, et al. The health effects of peace-keeping in the UK Armed Forces: Bosnia 1992-1996. Predictors of psychological symptoms. Psychol Med 2003; 33: 155-62.
23 Hotopf M, David A, Hull L, Nikalaou V, Unwin C, Wessely S. Risk factors fo continued illness among Gulf War veterans: a cohort study. Psychol Med 2004; 34: 747-54.

24 Iversen AC, Fear NT, Ehlers A, Hacker Hughes J, Hull L, Earnshaw M, et al Risk factors for post-traumatic stress disorder among UK Armed Forces personnel. Psychol Med 2008; 38: 511-22.

25 Ozer EJ, Best SR, Lipsey TL, Weiss DS. Predictors of posttraumatic stress disorder and symptoms in adults: a meta-analysis. Psychol Bull 2003; 129 52-73.

26 Ehlers A, Clark DM. A cognitive model of posttraumatic stress disorder. Behav Res Ther 2000; 38: 319-45.

27 Greenberg N, Jones N. Optimizing Mental Health Support in the Military: The Role of Peers and Leaders. American Psychiatric Association, 2009.

28 Britt TW, Davison J, Bliese PD, Castro CA. How leaders can influence the impact that stressors have on soldiers. Mil Med 2004; 169: 541-5.

29 Schwarzer R, Knoll N, Rieckmann N. Social support. In Health Psychology (eds A Kaptein \& J Weinman): 158-82. Blackwell, 2004.

30 Sharpley JG, Fear NT, Greenberg N, Jones M, Wessely S. Pre-deployment stress briefing: does it have an effect? Occup Med Oxford 2008; 58: 30-4.

31 Mental Health Advisory Team (MHAT) V. Operation Iraqi Freedom 06-08: Iraq. Operation Enduring Freedom 8: Afghanistan. Office of the Surgeon Multi-National Force-Iraq, Office of the Command Surgeon, Office of The Surgeon General United States Army Medical Command, 2008 (http://www.armymedicine.army.mil/reports/mhat/mhat_v/Redacted1MHATV-4-FEB-2008-Overview.pdf)

32 Greenberg N, Langston V, Fear NT, Jones M, Wessely S. An evaluation of stress education in the Royal Navy. Occup Med (Lond) 2009; 59: 20-4.

33 Henbest RJ, Stewart M. Patient-centredness in the consultation. 2: Does it really make a difference? Fam Pract 1990; 7: 28-33.

34 Solomon Z, Benbenishty R. The role of proximity, immediacy, and expectancy in frontline treatment of combat stress reaction among Israelis in the Lebanon War. Am J Psychiatry 1986; 143: 613-7.

35 Surgeon General's Policy Letter 3/06. The Prevention and Management of Traumatic Stress Related Disorders in Armed Forces Personnel Deployed on Operations. Ministry of Defence, 2006. 